\title{
Properties of Self-Compacting Concrete with Machine-Made Sand and High-Volume Mineral Admixtures
}

\author{
Zhengwu Jiang ${ }^{1, *}$, Shilong Mei ${ }^{2}$ \\ ${ }^{1}$ Key Laboratory of Advanced Civil Engineering Materials of Ministry of Education, Tongji University, Shanghai \\ 200092, China; ${ }^{2}$ Guizhou Expressway Development Corporation, Guiyang 550004, China
}

\begin{abstract}
Based on appropriate assessment methods and indexes of self-compacting concrete proposed, properties of concrete made with river-sand and machine-made sand was firstly compared in different mix proportions. The techniques such as basic parameters optimization of mix proportion, admixture composition, large-volume mineral admixtures addition for preparing machine-made sand self-compacting concrete (MSCC) were proposed, and effect of different factors on workability and compressive strength of MSCC was studied. The results indicate that requirements on parameters of mix proportion for MSCC are different from those of river-sand self-compacting concrete. Applying the techniques such as basic parameters optimization of mixture, admixture composition, high-volume mineral admixtures addition, MSCC with initial slump above $24 \mathrm{~cm}$, slump flow over $60 \mathrm{~cm}$, delivery time of inverted slump cone (DTIS) between $5 \mathrm{~s}$ and $15 \mathrm{~s}$, compressive strength above $60 \mathrm{MPa}$ at 28 days was prepared.
\end{abstract}

Keywords: Machine-made sand; self-compacting; concrete; mineral admixture; workability

\section{INTRODUCTION}

Concrete is the largest consuming construction material for buildings at present $[1,2]$. Being one of main components of concrete, sand generally includes natural sand and machine-made sand. However, natural sand, river sand as its largest portion, could not meet with the increasing demand for concrete production in some countries and regions, especially in southwest China. Meanwhile, over quarrying natural sand will undoubtedly damage the natural environment. Thus, the substitution of machine-made sand to river sand for preparing concrete has becoming a steady tendency in concrete industry [3,4]. Application research on machinemade sand for preparing concrete has carried out for so many years in several countries and regions. At present, machinemade sand has been applied in mortar, concrete and masonry blocks in some regions in China, particularly in places such as Yunnan and Guizhou provinces in southwest China, where river sand are scarce [3-7].

Due to excellent workability, mechanical property and durability, self-compacting concrete is extensively applied in concreting projects recently. Meanwhile, self-compacting concrete has become an important research and application aspect of high-performance concrete. In recent years, a number of research and application on self-compacting concrete have been carried out [8-11]. In addition, mineral admixtures, such as fly ash, slag powder and silica fume have become indispensable components for preparing highperformance concrete $[12,13]$. As to areas where are shortage of river sand, research on machine-made sand used in

*Address correspondence to this author at Key Laboratory of Advanced Civil Engineering Materials of Ministry of Education, Tongji University, 1239 Siping Road, Shanghai, China 200092; E-mail: jzhw@ tongji.edu.cn self-compacting concrete also becomes critical and important. MSCC has unique characteristics and requirements and differentiates from normal concrete in terms of materials, composition, mix proportion design, quality control and testing methods. Since sand is one of main components of selfcompacting concrete in volume, it affects properties of selfcompacting concrete certainly. As compared with river sand, machine-made sand features in poor gradation and texture, rough particles concentrated on two ends of graduation and high volume of rock powder. MSCC has its own distinctive properties. Therefore, research on preparation techniques and properties of machine-made sand self-compacting concrete with large-volume mineral admixtures is very significant to promote application of MSCC according to material properties of mineral admixtures and machine-made sand.

In this paper, properties of concrete made with river-sand and machine-made sand was compared in different mix proportions in the first study phase based on appropriate assessment methods. In the second study phase, effects of basic parameters of concrete mix proportion admixture type and dosage, mineral admixtures on workability and mechanical properties of MSCC. Then key technical parameters for machine-made sand self-compacting concrete with largevolume mineral admixtures are proposed.

\section{RAW MATERIALS}

In this experiment, An ordinary Portland cement corresponding to ASTM type 1 was used. Fly ash Class II with burning loss of $6.8 \%$ and specific surface area of $410 \mathrm{~m}^{2} / \mathrm{kg}$ and silica fume was used. Chemical components of cement and mineral admixtures are shown in Table 1. Polycarboxylate superplasticizer with solid content of $30 \%$, Welan viscosity-enhancing agent (VEA), de-foaming agent, airentrainment agent were employed. 
Table 1. Chemical Component of Cement and Mineral Admixtures (\%)

\begin{tabular}{|c|c|c|c|c|c|c|c|c|c|}
\hline Materials & $\mathbf{C a O}$ & $\mathbf{S i O}_{2}$ & $\mathbf{A l}_{2} \mathbf{O}_{3}$ & $\mathbf{S O}_{3}$ & $\mathbf{F e}_{2} \mathbf{O}_{3}$ & $\mathbf{M g O}$ & $\mathbf{K}_{2} \mathbf{O}$ & $\mathbf{T i O}_{2}$ & $\mathbf{N a}_{2} \mathbf{O}$ \\
\hline \hline Cement & 59.9 & 21.3 & 7.6 & 3.1 & 3.8 & 2.0 & 1.2 & 0.7 & 0.2 \\
\hline Fly ash & 3.3 & 44.1 & 26.8 & 0.9 & 10.2 & 0.9 & 2.4 & 2.4 & 0.9 \\
\hline Silica fume & 0.4 & 91.0 & 1.1 & 0.3 & 2.0 & 1.0 & 0.9 & - & 0.2 \\
\hline
\end{tabular}

Table 2. Physical Properties of River Sand and Machine-Made Sand

\begin{tabular}{|c|c|c|c|c|c|}
\hline Items & Packing Density $\left(\mathbf{g} / \mathrm{cm}^{\mathbf{3}}\right)$ & Apparent Density(g/cm $)$ & Crushing Index(\%) & $\begin{array}{c}\text { Modulus of } \\
\text { Fineness }\end{array}$ & $\begin{array}{c}\text { Content of Rock } \\
\text { Powder }(\%)\end{array}$ \\
\hline \hline River sand & 1.49 & 2.67 & 10.2 & 2.5 & 0.3 \\
\hline Machine-made sand & 1.61 & 2.70 & 14.1 & 3.5 & 9.2 \\
\hline
\end{tabular}

Distribution curves of particle sizes of cement, fly ash and silica fume are indicated in Fig. (1). It can be seen that distribution areas of particle diameters of them are different from each other. Specifically, particle diameter of silica fume is very small and narrowly distributed while that of fly ash is high and broadly distributed.

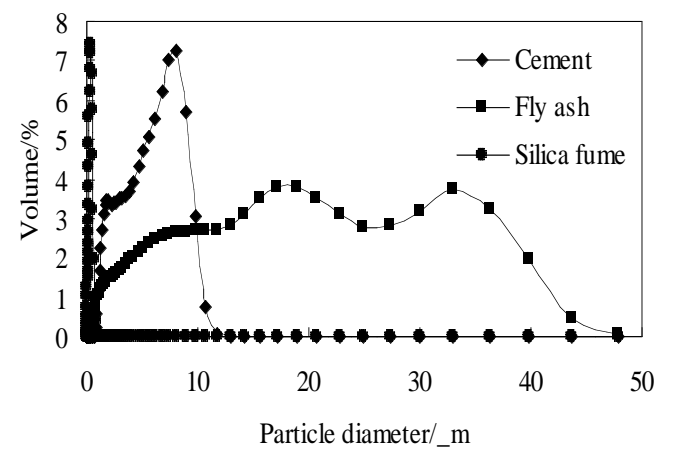

Fig. (1). Distribution of particle size of cement and mineral admixtures.

Machine-made sand as fine aggregate is made from rock of dolomite. It is an inactive aggregate. Basic physical properties of river sand and machine-made sand are shown in Table 2. Separate sieve residue and cumulative sieve residue

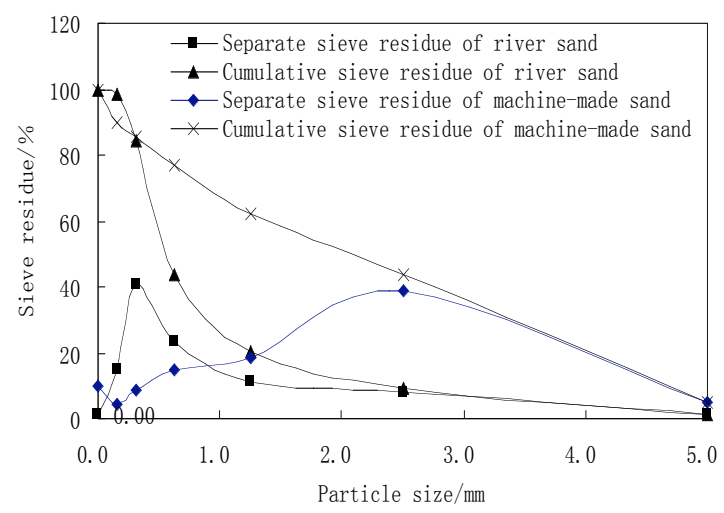

Fig. (2). Sieving curves of river sand and machine-made sand. of machine-made sand and river sand are shown in Fig. (2). As illustrated in this Fig. (2), content of rock powder in machine-made sand is very high and the gradation is not uniform.

Coarse aggregate made from dolomite rock with maximum size of $25 \mathrm{~mm}$, apparent density of $2.64 \mathrm{~g} / \mathrm{cm}^{3}$, bulk density of $1.52 \mathrm{~g} / \mathrm{cm}^{3}$, crushing index of $11.4 \%$ and soil content of $0.8 \%$ was used. To realize best aggregate gradation for preparing MSCC, gradation of coarse aggregate is divided into four sections: $5-10 \mathrm{~mm}, 10-16 \mathrm{~mm}, 16-20 \mathrm{~mm}$ and 20-25mm.

\section{EXPERIMENTAL METHODS}

\section{Testing Methods for Determining Workability Of Self-} Compacting Concrete

Three testing methods, slump, slump flow and DTIS, are adopted for assessing properties of self-compacting concrete mixtures. In this program, Basic requirements on workability of self-compacting concrete shall meet initial slump larger than $22 \mathrm{~cm}$, slump flow more than $55 \mathrm{~cm}$ and DTIS between $5 \mathrm{~s}$ and $15 \mathrm{~s}$.

\section{Testing Methods of Slump and Slump Flow}

Testing method for slump of concrete mixture is carried out according to Chinese specification GBJ80. Based on tested slump, slump flows at two vertical directions in horizontal plane are read and averaged as the final slump flow.

\section{Delivery Time of Inverted Slump Cone (DTIS)}

DTIS that was designed according to the characters of MSCC is an effective parameter to reflect viscosity and cohesiveness of fresh MSCC. The procedure of delivery time measurement is defined as follows: invert the slump cone on the supporter surface up to ground a certain height. Add fresh concrete into it fully. Then float it. Fix the slump cone and remove the supporter. And allow fresh concrete to flow out from the bottom mouth of the slump cone. The delivery time when all fresh concrete flows out is recorded using the stop watch (s). The delivery time could indicate plastic viscosity and yield value of self-compacting concrete mixture. DTIS testing method is practical, convenient and repeatable. 
Table 3. Properties of Concrete with River Sand or Machine-Made Sand

\begin{tabular}{|c|c|c|c|c|c|c|c|c|c|c|c|}
\hline \multirow{2}{*}{ Serial } & \multirow{2}{*}{ Sand Type } & \multirow{2}{*}{$\begin{array}{c}\text { Content of Fly } \\
\text { Ash } / \%\end{array}$} & \multicolumn{3}{|c|}{ Slump/cm } & \multicolumn{3}{|c|}{ Slump Flow/cm } & \multicolumn{3}{|c|}{ DTIS/s } \\
\hline & & & $\mathbf{0 h}$ & $1 \mathrm{~h}$ & $2 h$ & $\mathbf{0 h}$ & $1 \mathrm{~h}$ & $2 h$ & $\mathbf{0 h}$ & $1 \mathrm{~h}$ & $2 \mathrm{~h}$ \\
\hline SG1 & River sand & 20 & 26.0 & 25.5 & 23.5 & 70.0 & 68.0 & 65.5 & 7.1 & 9.8 & 13.5 \\
\hline SG2 & $\begin{array}{l}\text { Machine- } \\
\text { made sand }\end{array}$ & 0 & 21.0 & 16.0 & 13.5 & 55.0 & 31.0 & 28.0 & 38.0 & 58.5 & 195.0 \\
\hline
\end{tabular}

Table 4. Effect of w/b on Properties of Concrete with Machine-Made Sand

\begin{tabular}{|c|c|c|c|c|c|c|c|c|}
\hline Serial & $\begin{array}{c}\text { Ratio of Water to } \\
\text { Binder }\end{array}$ & \multicolumn{2}{|c|}{ Slump/cm } & \multicolumn{2}{|c|}{ Slump flow/cm } & \multicolumn{2}{|c|}{ DTIS/s } & Mixture Behavior \\
\hline SG6 & 0.35 & 23.5 & 23.0 & 64.0 & 58.0 & 12.1 & 15.1 & Good coherence \\
\hline SG7 & 0.32 & 24.5 & 22.5 & 65.0 & 55.0 & 18.0 & 26.0 & High viscosity \\
\hline
\end{tabular}

\section{Specimen Preparation, Curing and Testing}

A certain amount of sand, aggregate, cement and powder admixtures according to mix proportion in each batch is firstly mixed for half minute. Then water and superplasticizer are added in the continuous mixing process for two minutes for achieving designed slump. The workability of concrete mixture is tested and then it is put into specimen molds in the dimension of $10 \times 10 \times 10 \mathrm{~cm}$ without vibration.

After one day standard curing, specimens are removed from the molds. Then they are cured in standard way at curing room with the curing temperature $20 \pm 3^{\circ} \mathrm{C}$ and humidity no less than $90 \%$. Testing method for compressive strength of concrete is carried out according to Chinese specification GBJ82.

\section{PROPERTIES OF CONCRETE WITH RIVER SAND AND MACHINE-MADE SAND IN DIFFERENT MIX PROPORTIONS}

On the basis of a series of experiment, basic parameters of mix proportion of self-compacting concrete with river sand is determined as follows: ratio of water to cement is 0.35 ; sand ratio is $50 \%$; dosage of CS-SP1 superplasticizer is $1.2 \%$ by weight of total cementitious materials (the maximum size of coarse aggregate is $25 \mathrm{~mm}$; coarse aggregate gradation is $5-10 \mathrm{~mm}: 10-20 \mathrm{~mm}: 20-25 \mathrm{~mm}=30 \%: 40 \%: 30$ $\%$. Basic mix proportion of self-compacting concrete is cementitious material: sand: coarse aggregate: water: superplasticizer as 500: 860: 860: 175: $6\left(\mathrm{~kg} / \mathrm{m}^{3}\right)$. Workability properties of concrete with river sand and machine-made sand were investigated.

According to the results shown in Table $\mathbf{3}$ and observations during test, properties of concrete made with river sand perform well, which meets the requirement of self- compacting concrete. Problems are existed in concrete made with machine-made sand, such as slump and slump flow lower than requirements, long DTIS and high slump loss occurred in spite of the addition of large-volume fly ash. It illustrates that poorer cohesion and easier blockage exist in machine-made sand concrete compared with river sand selfcompacting concrete. Thus, it is necessary to adjust and optimize parameters and key techniques of mix proportion of MSCC for meeting the required properties of self-compacting concrete.

\section{OPTIMIZATION TECHNIQUES OF BASIC PA- RAMETERS OF MIX PROPORTION}

\section{Ratio of Water to Binder}

Basic parameters of MSCC are determined for tests as follows: maximum size of coarse aggregate is $20 \mathrm{~mm}$; sand ratio is $50 \%$; dosage of CS-SP1 superplasticizer is $1.2 \%$; content of fly ash is $40 \%$ and content of silica fume is $5 \%$. The workability results of concrete with machine-made sand with different ratios of w/b are shown in Table 4.

As it shows in Table 4, initial slump and slump flow are not changed largely with increasing ratio of $w / b$ from 0.32 to 0.4 while initial and 2-hour DTIS decrease first and increase then. This illustrates that concrete with machine-made sand is sensitive to the ratio of $w / b$. When the ratio of $w / b$ is small, concrete mixture becomes viscous. In contrast, segregation and bleeding occurred in concrete mixture with increasing the ratio of $\mathrm{w} / \mathrm{b}$. Meanwhile, DTIS becomes longer. All these indicate that workability properties of concrete with machine-made sand could not be improved if it only increases water content. Flowability and cohesion of concrete could not reach the SCC requirements if it only increases content of agents or ratio of w/c. it needs to adopt other techniques of admixture composition and large-volume 
Table 5. Effect of Sand Ratio on Properties of Concrete With Machine-Made Sand

\begin{tabular}{|c|c|c|c|c|c|c|c|c|c|c|c|c|c|c|}
\hline Serial & $\begin{array}{c}\text { Sand } \\
\text { Ratio/\% }\end{array}$ & $\begin{array}{l}\text { VEA } \\
1 \% 0\end{array}$ & \multicolumn{3}{|c|}{ Slump/cm } & \multicolumn{3}{|c|}{ Slump Flow/cm } & \multicolumn{3}{|c|}{ DTIS/s } & \multicolumn{3}{|c|}{ Compressive Strength/MPa } \\
\hline SG9 & 50 & 0.5 & 26.0 & 25.5 & 22.5 & 72.0 & 71.0 & 72.5 & 8.8 & 10.8 & 15.8 & 28.3 & 49.4 & 73.1 \\
\hline SG10 & 55 & 0 & 23.5 & 22.5 & 21.5 & 64.0 & 53.0 & 54.0 & 26.0 & 39.0 & 38.0 & 25.2 & 43.2 & 65.3 \\
\hline
\end{tabular}

Table 6. Mix Proportion of MSCC Different Graduations of Coarse Aggregate

\begin{tabular}{|c|c|c|c|c|c|}
\hline Serial & \multicolumn{2}{|c|}{ Superplasticizer } & \multicolumn{2}{|c|}{ Coarse Aggregate } & VEA/\% \\
\hline SG12 & \multirow[t]{2}{*}{ CS-SP1 } & 1.5 & 50 & 50 & 0.2 \\
\hline SG13 & & 1.5 & 40 & 60 & 0.5 \\
\hline
\end{tabular}

Table 7. Properties of MSCC with Different Graduations of Coarse Aggregate

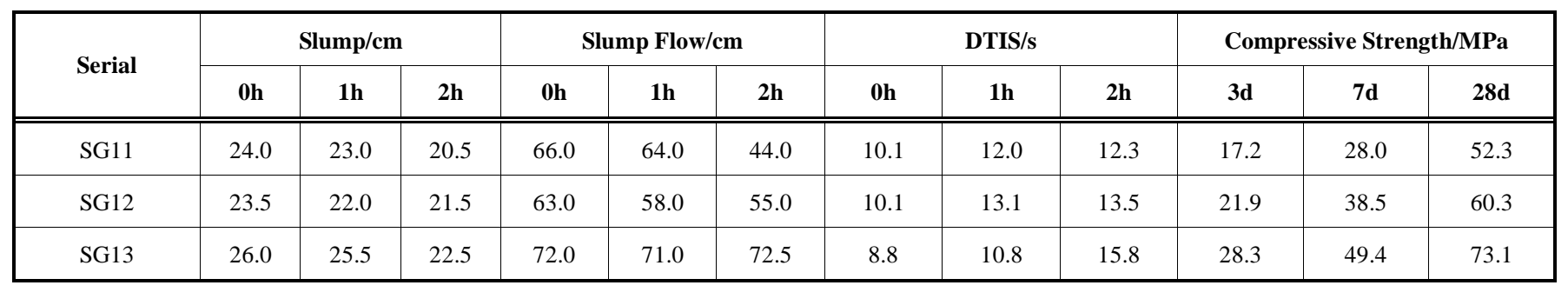

mineral admixtures addition to improve properties of selfcompacting concrete.

\section{Sand Ratio}

Parameters of mix proportion of self-compacting concrete are determined as follows: Ratio of $w / b$ is 0.35 . Content of fly ash is $40 \%$. Content of silica fume is $5 \%$. The dosage of superplasticizer is $1.5 \%$, and maximum size of aggregate is $20 \mathrm{~mm}$ and aggregate gradation: $5-10 \mathrm{~mm}: 10$ $20 \mathrm{~mm}$ is $40 \%: 60 \%$.

Based on the above mix proportion, content of viscosity enhancing agent is adjusted. Effect of different sand ratio on properties of concrete with machine-made sand is shown in Table 5.

As it shows in Table $\mathbf{5}$, when sand ratio of selfcompacting concrete is $45 \%$, it seems that bleeding and segregation of concrete mixture occurred while slump and slump flow are not good. Meanwhile, DTIS is relatively small. When sand ratio of self-compacting concrete reaches $50 \%$, slump and slump flow becomes very large and DTIS is reasonable. When sand ratio of self-compacting concrete reaches $55 \%$, viscosity of concrete becomes higher and other properties of concrete mixture also are good without adding viscosity enhancing agent. Meanwhile, flow value of concrete becomes higher. DTIS, however, is too high. Regarding the development of compressive strength, compressive strength of concrete at different ages increases first and de- creases then with the increase of sand ratio. Judging from the above analysis, sand ratio of MSCC should not be too low. It is suggested that sand ratio of MSCC is preferably approximate $50 \%$.

\section{Aggregate Gradation}

Based on the above mix proportion of concrete shown above, content of superplasticizer is adjusted. Effects of different graduations of coarse aggregate on properties of concrete with machine-made sand are shown in Table 6, 7.

As it shows in Table 6, 7, different graduations of coarse aggregate affect properties of self-compacting concrete mixture to some extent. With the decrease content of mediansize and small-size aggregates, flowability of self-compacting concrete becomes larger while the tendency of segregation also becomes distinctive. Thus it needs to add VEA for adjustment. From the development of compressive strength, compressive strength of self-compacting concrete becomes larger with the decrease of median-size and smallsize aggregates. In general, properties of MSCC are good when the maximum size of aggregate is within $20 \mathrm{~mm}$. It is found that comprehensive properties of MSCC is preferably good when the maximum size of aggregate is $200 \mathrm{~mm}$ and the aggregate gradation $5-10 \mathrm{~mm}: 10-20 \mathrm{~mm}$ is $50 \%: 50 \%$.

\section{Techniques of Admixture Composition}

Admixtures are key components of materials used for preparing high-performance self-compacting concrete. With 
Table 8. Effect of Types of Superplasticizer on Properties of MSCC

\begin{tabular}{|c|c|c|c|c|c|c|c|c|c|c|c|c|c|c|c|}
\hline \multirow{2}{*}{ Serial } & \multicolumn{2}{|c|}{ WRA } & \multirow{2}{*}{$\begin{array}{l}\text { VEA } \\
1 \% 0\end{array}$} & \multicolumn{3}{|c|}{ Slump/cm } & \multicolumn{3}{|c|}{ Slump flow/cm } & \multicolumn{3}{|c|}{ DTIS/s } & \multicolumn{3}{|c|}{$\begin{array}{c}\text { Compressive } \\
\text { strength/MPa }\end{array}$} \\
\hline & Type & Dosage/\% & & $\mathbf{0 h}$ & $1 \mathrm{~h}$ & $\mathbf{0 h}$ & $1 \mathrm{~h}$ & $2 \mathrm{~h}$ & $2 h$ & $\mathbf{0 h}$ & $1 \mathrm{~h}$ & $2 \mathrm{~h}$ & $3 d$ & $7 d$ & 28d \\
\hline SG14 & LX-6 & 1.6 & 10 & 24 & 23.5 & 20.5 & 61 & 56 & 42 & 12 & 14.1 & 18 & 18.9 & 36.5 & 55.3 \\
\hline SG15 & CS-SP1 & 1.4 & 2 & 23.5 & 22.0 & 21.5 & 63 & 58 & 55 & 10.1 & 13.1 & 13.5 & 21.9 & 38.5 & 60.3 \\
\hline SG16 & V500 & 2.0 & 5 & 25.5 & 23.5 & 23.5 & 65 & 66 & 64 & 7.3 & 7.7 & 10 & 20.5 & 28.5 & 51.6 \\
\hline SG17 & V3320 & 1.5 & 20 & 23.5 & 22.0 & 20.0 & 60 & 56 & 50 & 21 & 27.6 & 31.4 & 20.5 & 36.7 & 54.7 \\
\hline
\end{tabular}

Table 9. Effect of Composite Addition of Superplasticizer and Viscosity-Enhancing Agent on Properties of MSCC

\begin{tabular}{|c|c|c|c|c|c|c|c|c|c|c|c|c|c|c|c|}
\hline \multirow[t]{2}{*}{ Serial } & \multicolumn{2}{|c|}{ WRA } & \multirow{2}{*}{$\begin{array}{l}\text { VEA } \\
1 \% 0\end{array}$} & \multicolumn{3}{|c|}{ Slump/cm } & \multicolumn{3}{|c|}{ Slump flow/cm } & \multicolumn{3}{|c|}{ DTIS/s } & \multicolumn{3}{|c|}{$\begin{array}{c}\text { Compressive } \\
\text { strength/MPa }\end{array}$} \\
\hline & Type & Dosage/\% & & $\mathbf{0 h}$ & $1 \mathrm{~h}$ & $\mathbf{0 h}$ & $1 \mathrm{~h}$ & $2 \mathrm{~h}$ & $2 \mathrm{~h}$ & $\mathbf{0 h}$ & $1 \mathrm{~h}$ & $2 \mathrm{~h}$ & 3d & $7 d$ & 28d \\
\hline SG18 & \multirow{2}{*}{ V3320 } & \multirow{2}{*}{1.5} & 0 & 24 & 22 & 30 & 48 & 45 & 42 & 30 & 33 & 36.3 & - & - & - \\
\hline SG18-1 & & & 0.1 & 24.5 & 24 & 25.5 & 65 & 60 & 58 & 25.5 & 28 & 31.1 & 20.5 & 36.7 & 54.7 \\
\hline SG19-1 & CS-SP1 & 1.2 & 0.2 & 23 & 23.5 & 11.1 & 57 & 55 & 54 & 11.1 & 12.5 & 14.1 & 18.9 & 36.5 & 55.3 \\
\hline
\end{tabular}

the addition of admixtures, such as superplasticizer, VEA and defoamer, MSCC could achieve proper viscosity, good flowability and cohesion, plastic and mechanical properties under lower ratio of $\mathrm{w} / \mathrm{b}$.

\section{Types of Superplasticizer}

Parameters of mix proportion of MSCC are determined as follows: sand ratio is $50 \%$; ratio of $\mathrm{w} / \mathrm{b}$ is 0.35 ; dosage of CS-SP1 superplasticizer is $1.2 \%$; content of fly ash is $40 \%$; content of silica fume is 5\%; maximum size of aggregate is $20 \mathrm{~mm}$ and aggregate gradation of $5-10 \mathrm{~mm}: 10-20 \mathrm{~mm}$ is $50 \%: 50 \%$. Based on the above mix proportion, content of superplasticizer is adjusted to keep initial slump about $23 \pm 1 \mathrm{~cm}$. Effects of four types of polycarboxylate superplasticizer, namely, LX-6, CS-SP1, V500, V3320 on properties of concrete are shown in Table $\mathbf{8}$.

As it shows in Table $\mathbf{8}$, concrete added with SP1 and V500 superplasticizer is relatively good with less loss of slump flow. Judging from DTIS, concrete added with V500 superplasticizer has the shortest DTIS. Then it is concrete added with CS-SP1 superplasticizer. In contrast, concrete added with LX-6 and V3320 superplasticizers shares larger average values on DTIS, which indicates that concrete mixture is too viscous. Judging from compressive strength, compressive strengths of concrete added with CS-SP1 superplasticizer at the age of 3 days, 7 days and 28 days are highest. Considering properties of concrete mixture and mechanical properties, properties of CS-SP1 polycarboxylate superplasticizer are best.

\section{Viscosity Enhancing Agent (VEA)}

VEA is a necessary admixture for preparing selfcompacting concrete, particularly for MSCC. Under the same conditions, Effect of composite addition of superplasticizer and VEA in different dosages on properties of MSCC are shown in Table 9.

As it shows in Table 9, concrete added with V3320 superplasticizer and without VEA, slump flow reaches $48 \mathrm{~cm}$ and segregation is occurred although slump reaches $24 \mathrm{~cm}$. In addition, DTIS is up to 30 seconds. After added a certain amount of VEA, workability of concrete is much improved and slump flow also increases to $65 \mathrm{~cm}$. It almost reaches the requirements except of a little longer of DTIS. As to concrete added with CS-SP1 superplasticizer and VEA, its properties are improved in general, much shorter of DTIS in particular. Judging from the tendency of strength, early strength of concrete will be reduced with VEA while the later strength will be not affected. It indicates that it is necessary to add certain amount of VEA into MSCC to improve properties.

\section{TECHNIQUES OF LARGE-VOLUME MINERAL ADMIXTURES ADDITION}

\section{Types and Content of Mineral Admixtures}

Based on the above mix proportion shown above, effects of single addition and composite addition of different mineral admixtures on properties of MSCC are shown in Table 10 .

As it shows in Table $\mathbf{1 0}$ and Table 11, when content of fly ash reaches $20 \%$, silica fume $3 \%$ and admixtures $1.5 \%$, water bleeding and segregation are occurred while DTIS becomes too long and viscosity is too small. After a certain amount of VEA is added, viscosity of concrete is improved. Segregation, however, still exists to some extent. When it increases the amount of fly ash and silica fume and adjusts content of admixture, good properties of concrete could be 
Table 10. Mix Proportion of MSCC With Different Mineral Admixtures

\begin{tabular}{|c|c|c|c|c|c|c|}
\hline Serial & Content of Fly Ash/\% & $\begin{array}{c}\text { Content of Silica } \\
\text { Fume/\% }\end{array}$ & \multicolumn{2}{|c|}{ Grade of Coarse Aggregate } & $\begin{array}{r}\text { CS-SP1 } \\
\text { WRA/\% }\end{array}$ & VEA/\%o \\
\hline SG21 & 20 & 3 & $40 \%$ & $60 \%$ & 1.5 & 0.5 \\
\hline $\mathrm{SG} 22$ & 40 & 5 & $40 \%$ & $60 \%$ & 1.2 & 0.6 \\
\hline $\mathrm{SG} 24$ & 40 & 8 & $50 \%$ & $50 \%$ & 1.5 & 0.05 \\
\hline $\mathrm{SG} 25$ & 40 & 10 & $50 \%$ & $50 \%$ & 1.2 & - \\
\hline
\end{tabular}

Table 11. Properties of MSCC with Different Mineral Admixture

\begin{tabular}{|c|c|c|c|c|c|c|c|c|c|}
\hline \multirow{2}{*}{ Serial } & \multicolumn{2}{|c|}{ Slump/cm } & \multicolumn{2}{c|}{ Slump flow/cm } & \multicolumn{3}{c|}{ DTIS/s } & \multicolumn{2}{c|}{ Compressive Strength/MPa } \\
\cline { 2 - 10 } & $\mathbf{0 h}$ & $\mathbf{2 h}$ & $\mathbf{0 h}$ & $\mathbf{2 h}$ & $\mathbf{0 h}$ & $\mathbf{2 h}$ & $\mathbf{3 d}$ & $\mathbf{7 d}$ & $\mathbf{2 8 d}$ \\
\hline \hline SG20 & 24.0 & 24.0 & 67.0 & 66.0 & 37.5 & 68.5 & 23.1 & 44.1 & 59.3 \\
\hline SG21 & 25.5 & 22.5 & 71.0 & 72.5 & 27.8 & 53.8 & 28.2 & 49.4 & 58.3 \\
\hline SG22 & 24.5 & 23.0 & 62.0 & 53.5 & 10.6 & 13.7 & 14.9 & 27.5 & 51.1 \\
\hline SG23 & 24.5 & 23.0 & 66.0 & 52.0 & 6.4 & 6.1 & 18.2 & 32.2 & 55.6 \\
\hline SG24 & 23.0 & 23.0 & 62.0 & 58.0 & 15.0 & 32.7 & 17.1 & 35.1 & 53.7 \\
\hline SG25 & 21.5 & 19.5 & 45.0 & 34.0 & 12.9 & 20.5 & 16.4 & 28.8 & 59.3 \\
\hline
\end{tabular}

Table 12. Effect of the Amount of Cementitious Material on Workability Properties of MSCC

\begin{tabular}{|c|c|c|c|c|c|c|c|c|c|c|c|}
\hline \multirow{2}{*}{ Serial } & \multirow{2}{*}{ ACE/kg $\mathbf{m}^{-3}$} & \multirow{2}{*}{ VEA/\% } & \multicolumn{3}{|c|}{ Slump/cm } & \multicolumn{3}{|c|}{ Slump flow/cm } & \multicolumn{2}{|c|}{ DTIS/s } \\
\cline { 5 - 11 } & & & $\mathbf{0 h}$ & $\mathbf{1 h}$ & $\mathbf{2 h}$ & $\mathbf{0 h}$ & $\mathbf{1 h}$ & $\mathbf{2 h}$ & $\mathbf{0 h}$ & $\mathbf{1 h}$ & $\mathbf{2 h}$ \\
\hline \hline SG26-1 & 450 & 0.2 & 23.5 & 23.0 & 21.0 & 65.0 & 63.0 & 51.0 & 14.3 & 16.0 & 19.1 \\
\hline SG26-2 & 450 & 0.3 & 22.0 & 21.5 & 20.5 & 62.0 & 58.0 & 46.5 & 15.3 & 18.0 & 35.5 \\
\hline SG27 & 500 & 0 & 22.0 & 20.5 & 19.0 & 68.0 & 58.0 & 53.0 & 14.8 & 16.4 & 19.5 \\
\hline SG27-1 & 500 & 0.1 & 25.0 & 24.5 & 23.0 & 68.0 & 62.0 & 53.5 & 8.8 & 10.6 & 23.7 \\
\hline SG28-1 & 550 & 0.05 & 25.5 & 25.5 & 23.0 & 69.0 & 67.5 & 60.0 & 5.0 & 5.6 & 8.5 \\
\hline SG28-2 & 550 & 0.1 & 24.5 & 24.0 & 22.0 & 68.0 & 67.0 & 62.0 & 6.6 & 8.0 & 15.0 \\
\hline
\end{tabular}

achieved. When the amount of silica fume continuously increases, cohesion will be increased. But if silica fume is added too much, that is to say, when it is up to $8 \%$, viscosity will be remarkably increased while flow value will become smaller. When $40 \%$ fly ash and $5 \%$ silica fume are added into MSCC, workability of MSCC will be improved effectively. Compressive strength of MSCC at later ages increases quickly although it is a little low at early ages. Therefore, techniques of large-volume mineral admixtures addition are critical to prepare MSCC.

\section{Amount of Cementitious Material (ACE)}

The amount of cementitious material will significantly affect physical and mechanical properties of MSCC. Based on the above mix proportion given above, effects of the amount of cementitious material on properties of MSCC are shown in Table 12, 13.

As it shows in Table 12, 13, when the amount of cementitious material is small, slump and slump flow could not reach the requirements of SCC. With increasing the amount of cementitious material, properties of mixture of selfcompacting concrete become better while slump and slump flow could reach ideal values with short DTIS. It indicates that the higher the amount of cementitious material, the better the workability of MSCC is. Judging from compressive strength, although compressive strength of every set of sample concrete at 28 days is over $50 \mathrm{MPa}$, compressive strength 
Table 13. Effect of the Amount of Cementitious Material on Compressive Strength of MSCC

\begin{tabular}{|c|c|c|c|c|}
\hline \multirow{2}{*}{ Serial } & \multirow{2}{*}{ ACE/kg $\cdot \mathbf{m}^{-3}$} & \multicolumn{3}{|c|}{ Compressive strength/MPa } \\
\cline { 3 - 5 } & & $\mathbf{3 d}$ & $\mathbf{7 d}$ & 33.9 \\
\hline \hline SG26-2 & 450 & 15.7 & 37.7 & 54.3 \\
\hline SG27-1 & 500 & 21.9 & 33.2 & 51.3 \\
\hline SG28-2 & 550 & 17.1 & 55.8 \\
\hline
\end{tabular}

of concrete at different ages does not increase with the increase of the amount of cementitious material. When the amount of cementitious material reaches $500 \mathrm{~kg} / \mathrm{m}^{3}$, compressive strength at each age is the highest.

\section{CONCLUSIONS}

Machine-made sand features in much content of rock powder, rough surface and poor graduation. Basic parameters of mix proportion of MSCC are different from that of self-compacting concrete with river sand.

Ratio of water to binder significantly affects flowability and cohesion of MSCC. As to MSCC, sand ratio shall not be too low while the maximum size of aggregate and aggregate gradations critical parameters to affect workability and mechanical properties of MSCC.

The techniques, such as composite addition of superplasticizer and viscosity enhancing agent and composite addition of large-volume fly ash and silica fume will effectively improve flowability, cohesion and mechanical properties of MSCC.

Applying the techniques such as optimization on basic parameters of mix proportion, admixture composition, highvolume mineral admixtures addition, MSCC with initial slump over $24 \mathrm{~cm}$, slump flow over $60 \mathrm{~cm}$, DTIS between $5 \mathrm{~s}$ and $15 \mathrm{~s}$, compressive strength above $60 \mathrm{MPa}$ could be prepared.

\section{ACKNOWLEDGEMENT}

The authors gratefully acknowledge the support provided by National Natural Science Foundation of China (50508029).

\section{REFERENCES}

[1] P. K. Mehta and P. C. Aitcin, "Principles Underlying Production of High-Performance Concrete", Cement, Concrete and Aggregate, vol. 12, pp. 70-78, February 1990.
[2] Z. W. Jiang, Z. P. Sun and P. M. Wang, "Autogenous Relative Humidity Change and Autogenous Shrinkage of High-Performance Cement Pastes", Cement and Concrete Research, vol. 35, pp. 153945, August 2005

[3] X. S. Chen, "Application of Machine-Made Sand in Commercial Concrete", Engineering Machinery (in Chinese), vol. 35, pp. 74-75, November 2004

[4] J. Xu, J. Cai, J. L. Wang and M. K. Zhou, "State-of-art review on Machine-Made Sand and Concrete with Machine-Made Sand", Science and Technology of Foreign Construction Materials (in Chinese), vol. 25, pp. 20-24, March 2004.

[5] D. C. Xu, S. Q. Tu and D. L. Liu, "Discussions on Application and Mechanism of Machine-Made Sand in Concrete and Mortar", Engineering Science and Technology (in Chinese), pp. 69-73, February 2003.

[6] D. Q. Zhou, Y. Dao, G. Hua, K. Ming and J. P. Tian, "Research on Mix Proportion Design of High-Performance Concrete with Machine-Made Sand", Science and Technology of Foreign Construction Materials (in Chinese), vol. 26, pp. 20-23, March

[7] B065. Wang and J. Kong, "Mix Proportion Design and Construction Control on Pumping Concrete with Machine-Made Sand (in Chinese)", Journal of Shangdong Communications College, vol. 10, pp. 72-4, July 2002.

[8] V. Corinaldesi and G. Moriconi, "Durable Fiber Reinforced SelfCompacting Concrete", Cement and Concrete Research, vol. 34, pp. 249-54, February 2004.

[9] V. K. Bui and D. Montgomery I. Hinczak and K. Turner, "Rapid Testing Method for Segregation Resistance of Self-Compacting Concrete", Cement and Concrete Research, vol. 32, pp. 1489-96, September 2002.

[10] H. J. Wu and Z. G. Li, "Self-Compacting Concrete and its Workability (in Chinese)", Journal of Wuhan Institute of Technology, vol. 23, pp. 68-72, April 2004.

[11] Z. W. Yu, Z. H. Pan, Y. J. Xie and B. J. Liu, "Tentative Discussions on Calculation Methods for Mix proportion of HighPerformance Self-Compacting Concrete (in Chinese)", Concrete, pp. 54-57, 67, January 2004.

[12] Z. W. Jiang, Z. P. Sun and P. M. Wang, "Research on SelfDesiccation Effect of High-Performance Concrete (in Chinese)", Journal of Building Material, vol. 7, pp. 19-24, September 2004.

[13] Z. W. Jiang and Z. P. Sun, "Effect of Slag Powder Substituting Cement on Properties of High-Efficient Superplasticizer (in Chinese)", Journal of Building Material, vol. 6, pp. 231-6, September 2003.

(C) Jiang and Mei; Licensee Bentham Open.

This is an open access article distributed under the terms of the Creative Commons Attribution License (http://creativecommons.org/licenses/by/2.5/), which permits unrestrictive use, distribution, and reproduction in any medium, provided the original work is properly cited. 